
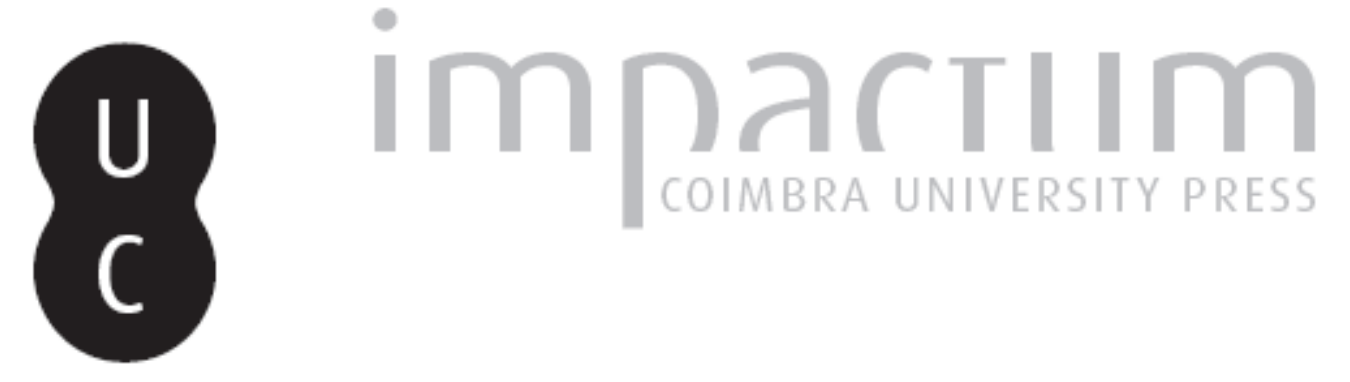

\title{
Conhecimento e cartografia da espessura das formações superficiais na área de Pensalvos (Serra do Alvão, norte de Portugal)
}

Autor(es): $\quad$ Martins, Bruno; Santos, Patrícia; Rebelo, Fernando

Publicado por: Associação Portuguesa de Riscos, Prevenção e Segurança

URL persistente:

URI:http://hdl.handle.net/10316.2/35123

DOI:

DOI:http://dx.doi.org/10.14195/1647-7723_21_9

Accessed : $\quad$ 26-Apr-2023 09:35:29

A navegação consulta e descarregamento dos títulos inseridos nas Bibliotecas Digitais UC Digitalis, UC Pombalina e UC Impactum, pressupõem a aceitação plena e sem reservas dos Termos e Condições de Uso destas Bibliotecas Digitais, disponíveis em https://digitalis.uc.pt/pt-pt/termos.

Conforme exposto nos referidos Termos e Condições de Uso, o descarregamento de títulos de acesso restrito requer uma licença válida de autorização devendo o utilizador aceder ao(s) documento(s) a partir de um endereço de IP da instituição detentora da supramencionada licença.

Ao utilizador é apenas permitido o descarregamento para uso pessoal, pelo que o emprego do(s) título(s) descarregado(s) para outro fim, designadamente comercial, carece de autorização do respetivo autor ou editor da obra.

Na medida em que todas as obras da UC Digitalis se encontram protegidas pelo Código do Direito de Autor e Direitos Conexos e demais legislação aplicável, toda a cópia, parcial ou total, deste documento, nos casos em que é legalmente admitida, deverá conter ou fazer-se acompanhar por este aviso.

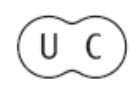




\section{territorium}

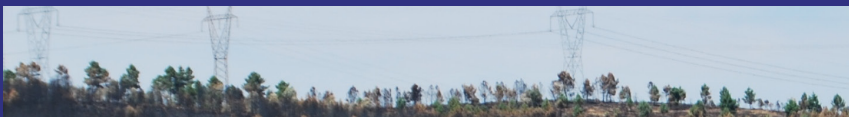

y

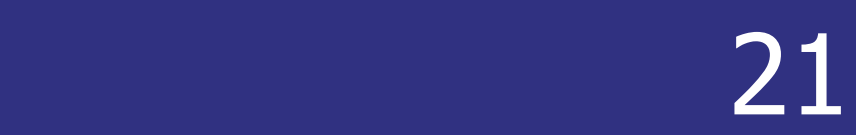

Territórios de risco: processos, vulnerabilidades e segurança

Revista da Associação Portuguesa de Riscos, Prevenção e Segurança 


\section{CONHECIMENTO E CARTOGRAFIA DA ESPESSURA DAS FORMAÇÕES SUPERFICIAIS NA ÁREA DE PENSALVOS (SERRA DO ALVÃO, NORTE DE PORTUGAL)*}

Bruno Martins

CEGOT e Departamento de Geografia da FLUC bruno.martins@uc.pt

Patrícia Santos

Centro de Geologia da Universidade do Porto patricia-santos@netcabo.pt

Fernando Rebelo

Professor Jubilado de Geografia da FLUC

fsrebelo@ci.uc.pt

\section{RESUMO}

Neste artigo é feita uma caracterização das principais formações superficiais encontradas na vertente norte da serra do Alvão: (i) depósitos de vertente e (ii) mantos de alteração a partir da análise macroscópica, granulométrica, química mineralógica. Pretende-se ainda produzir um mapa de espessura das formações superficiais com recurso à krigagem ordinária a partir da recolha de 48 pontos de amostragem posteriormente inseridos em tabela, e tratados com o auxílio de Sistemas de Informação Geográfica (SIG).

Palavras-chave: Formações superficiais; cartografia; depósitos de vertente; mantos de alteração; krigagem ordinária.

\section{RESUMEN}

Conocimiento y cartografía de la espesura de las formaciones superficiales en el área de Pensalvos (sierra do Alvão, norte de Portugal) - En este artículo ha sido hecha una caracterización de las principales formaciones superficiales que se han encontrado en la vertiente Norte de la sierra do Alvão: (i) depósitos de vertiente y (ii) mantos de alteración a partir del analice microscópico, granulométrico, químico mineralógico. Se pretende también producir un mapa de espesura de las formaciones generales con recurso a krigagem ordinaria a partir de 48 puntos de muestreo, posteriormente inseridos en una tabla y que se van a discurrir con el auxilio a Sistemas de Información Geográfica (SIG).

Palabras clave: Formaciones superficiales; cartografía; depósitos de vertiente; mantos de alteración; krigagem ordinária.

\section{RÉSUMÉ}

Connaissance et cartographie de l'épaisseur des formations superficielles à la surface de Pensalvos (montagne do Alvão, au nord du Portugal) - En cet article est faite une caractérisation des principales formations superficielles à la versant nord de la montagne do Alvão : (i) dépôts de versant et (ii) houppelandes de altération à partir de la analyse macroscopique, granulométrique, chimique minéralogique, On prétend aussi produire une carte d'épaisseur des formations superficielles avec le recours à krigagem ordinaire à partir du rentrage de 48 points d'échantillonnage, postérieurement inclus dans une table et traités avec l'aide de Systèmes d'Information Géographique (SIG).

Mots-clé: Formaciones superficiales; cartografía; depósitos de vertiente; mantos de alteración; krigagem ordinária.

\section{ABSTRACT}

Knowledge and thickness of superficial formations mapping in the area Pensalvos (saw Alvão, north of Portugal) - In this article we try to characterize the main superficial formations found in the northern part of the Alvão mountain: (i) slope deposits and (ii) weathering profiles. We also intend to produce a thickness of the superficial formations map using the ordinary kriging from the collection of 48 sampling points later inserted into the table, and treated by Geographic Information Systems (GIS).

Keywords: Superficial formations ; cartography; slope deposits; weathering profiles; ordinaries kriging.

* O texto deste artigo corresponde à comunicação apresentada ao VII Encontro Nacional de Riscos e I Forum ISCIA, tendo sido submetido em 01-11-2013, sujeito a revisão por pares a 14-02-2014 e aceite para publicação em 08-05-2014.

Este artigo é parte integrante da Revista Territorium, n. ${ }^{\circ} 21,2014,{ }^{\circ}$ RIscos, ISBN: 0872- 8941. 


\section{Introdução}

O estudo e a cartografia das formações superficiais é fundamental quer ao nível do conhecimento geomorfológico quer como ferramenta aplicada ao ordenamento do território. A cartografia deste tipo de formações acarreta desafios que se prendem com a heterogeneidade deste tipo de material e com a aplicação de modelações geoestatísticas em áreas pouco homogéneas e isotrópicas, quer do ponto de vista litológico quer morfológico, como é o caso da área de estudo.

Neste artigo é feita uma caracterização das principais formações superficiais encontradas na vertente norte da serra do Alvão: (i) depósitos de vertente e (ii) mantos de alteração. A análise granulométrica, química e mineralógica, aliada à análise macroscópica de alguns depósitos, permitiu inferir sobre as condições paleogeográficas e paleoclimáticas que estiveram na sua génese e identificar as principais linhas de meteorização.

Pretende-se ainda produzir um mapa de espessura das formações superficiais com recurso à krigagem ordinária a partir da recolha de 48 pontos de amostragem, uma vez que são variadas as potencialidades deste tipo de cartografia, em especial ao estudo de riscos geomorfológicos, como os de ravinamento, deslizamento e fluxos (de terra e detríticos), tornando-se assim um instrumento de grande utilidade no ordenamento do território.

\section{Localização da área em estudo}

A área de estudo corresponde à vertente norte da serra do Alvão, na proximidade das povoações de Pensalvos e Parada de Monteiros, na margem direita do rio Avelames (fig. 1). A área é talhada na sua maioria sobre o Granito de Vila Pouca de Aguiar (GVPA) e do Minhéu (GM) e sobre os metassedimentos incluídos na formação pelitograuváquica do Silúrico. Trata-se de uma formação constituída por xistos cinzentos com intercalações de xistos negros, ampelitos e liditos, com alternância de pelitos psamíticos, grauvaques e tufos vulcânicos (Pereira, 1988).

Em termos geotectónicos, esta área pertence à Zona Galiza-Trás-os-Montes (ZGTM) (FARIAs et al., 1985; ARENAS et al., 1988), incluída na Zona Centro-Ibérica (ZCI) (JULIVERT et al., 1974).

Do ponto de vista litológico, é constituída por duas unidades: a unidade metassedimentar e as rochas granitóides. A primeira integra formações pertencentes ao complexo autóctone da Zona Centro Ibérica (ZCI) e parautóctone da Zona Galiza-Trás-os-Montes (ZGTM) (Pereira, 1988), a segunda integra os granitóides hercínicos biotíticos com plagioclase cálcica e diferenciados, associados à fraturação frágil tardi-hercínica, bem como os granitóides hercínicos de duas micas, sin-tectónicos (GM) e tardi a pós-tectónicos (GVPA).

A morfologia da área está relacionada com o desligamento esquerdo tardi-varisco, Verin-Penacova, pertencente ao mesmo sistema de fraturas do acidente Bragança -Vilariça - Manteigas, sendo-lhe subparalelo, de orientação geral NNE-SSW.

\section{Metodologia}

A metodologia baseou-se no desenvolvimento das seguintes etapas: (i) selecção dos perfis/depósitos; (ii) análise in loco dos diferentes perfis/depósitos; (iii) recolha e análise laboratorial de amostras; (iv) determinação pontual das espessuras das formações superficiais (pontos de amostragem) e (v) modelação geoestatística.

A análise macroscópica dos perfis procurou caraterizar os diferentes níveis de meteorização (W) que constituem cada um deles e apresentar as características da rocha
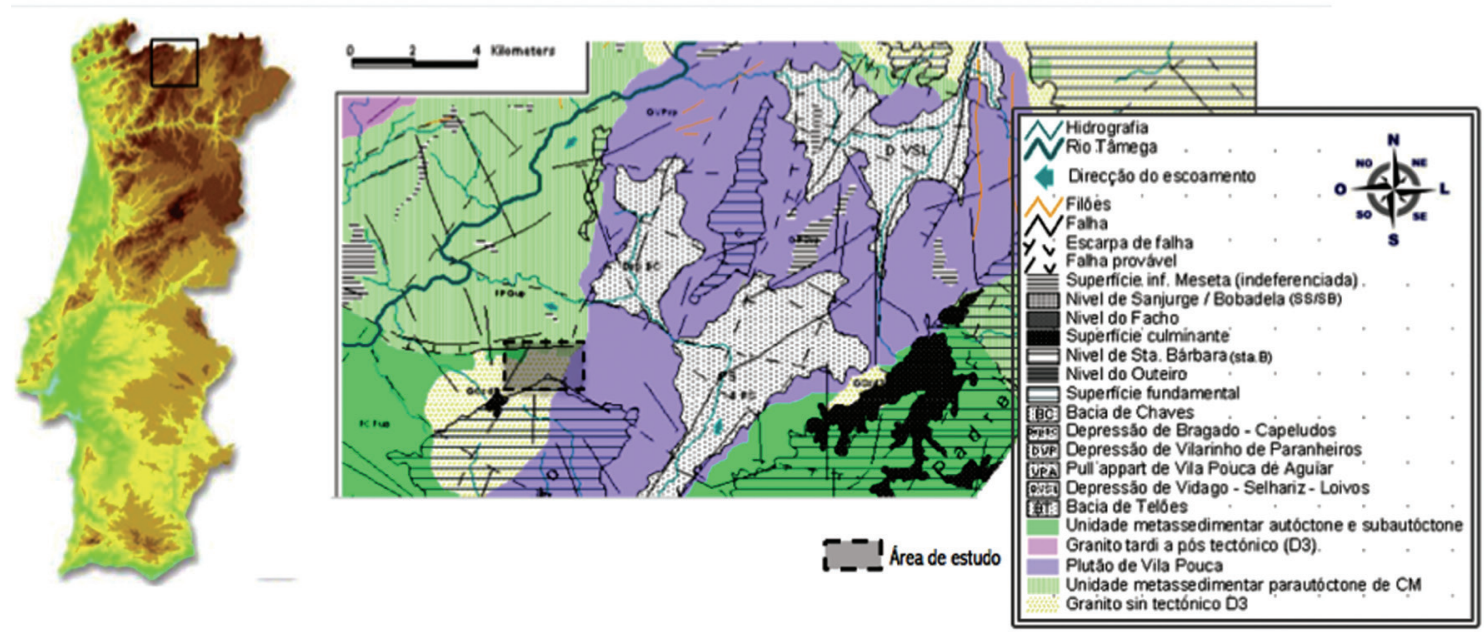

Fig. 1 - Localização e enquadramento morfo-estrutural da área de estudo. Fonte: B. MARTINS, 2010. 
alterada, acompanhada de uma análise das principais características geomorfológicas da vertente e do tipo de ocupação e uso do solo. Para maior uniformização deste tipo de análise, elaborou-se uma ficha de registo de campo utilizada para todos os perfis. Para avaliar os diferentes graus de alteração e as características do perfil e/ou horizontes de alteração (W) foi utilizada a classificação proposta por ISRM (1980) e IEAG (1981), segundo uma escala que varia entre I e VI (de fresco a solo residual).

O trabalho laboratorial passou pela análise granulométrica, química e mineralógica da fracção argilosa das amostras recolhidas.

Com o objectivo de cartografar as espessuras das formações superficiais para a área em estudo, procedeuse à amostragem de 48 perfis, determinando-se o respectivo posicionamento geográfico. Para cada perfil, foi preenchida uma ficha com o registo da espessura média da formação em causa, bem como com outros elementos complementares: declive, exposição, geologia, uso do solo e outros elementos considerados relevantes.

O tratamento geo-estatístico dos dados foi conseguido, recorrendo à ferramenta Geostatistycal Analyst, do ArcGis. Este tratamento teve como objectivo a elaboração do modelo de cartografia de distribuição de espessuras das formações superficiais, a partir de 48 dados pontuais. Selecionou-se o método de krigagem ordinária. Penizek \& Boruvka (2004) compararam vários métodos geoestatísticos na previsão da espessura do solo, tendo concluído que as melhores previsões eram conseguidas recorrendo à krigagem ordinária e à cokrigagem. A krigagem ordinária tem demonstrado, ainda, ser mais adequada na estimação de valores em locais não amostrados (Webster, 2008).

\section{Depósitos de vertente}

$\mathrm{Na}$ vertente norte da serra do Alvão foram estudados e descritos diversos depósitos que se relacionam com a atuação do frio (MARTins, 2010). A evolução finiquaternária da vertente, associando a descrição de cada nível aos processos geomorfológicos, principais responsáveis pela sua formação, pode ser resumida numa coluna estratigráfica (fig. 2).

A análise dos diferentes depósitos encontrados confirma a ideia das flutuações das condições climáticas operadas ao longo dos tempos mais recente do Quaternário, tanto no conjunto da Europa (Lowe \& Walker, 1984; Chaline, 1985, etc.) como, especificamente, em Portugal (DAVEAU, 1971, 1973; Rebelo, 1985, 1986, 2007; Cordeiro, 1986a, 1986b, 1990; 1992, 1995; Pedrosa, 1993; VIeIRA, 2000; 2004; Pedrosa et al., 2007, entre outros).

\section{Depósito de Pensalvos}

A génese do nível inferior do depósito de Pensalvos (fig. 3) ocorreu, muito provavelmente, em condições climáticas do tipo periglaciar. No entanto, a análise micromorfológica não permite afirmar que o gelo tenha tido influência no transporte dos materiais ao longo das vertentes. Admitimos, portanto, que a gelifluxão não terá sido o processo responsável pela movimentação dos materiais. Entre o nível inferior e o nível superior, verifica-se a existência de um paleossolo, com a muito provável incisão de um ravinamento.

A percentagem da fracção silto-argilosa no conjunto dos dois níveis do depósito é elevada. Mas há diferenças de pormenor entre eles (fig. 4) - o aumento da percentagem da caulinite na fracção argilosa do nível superior sugere que os valores da precipitação e da temperatura seriam

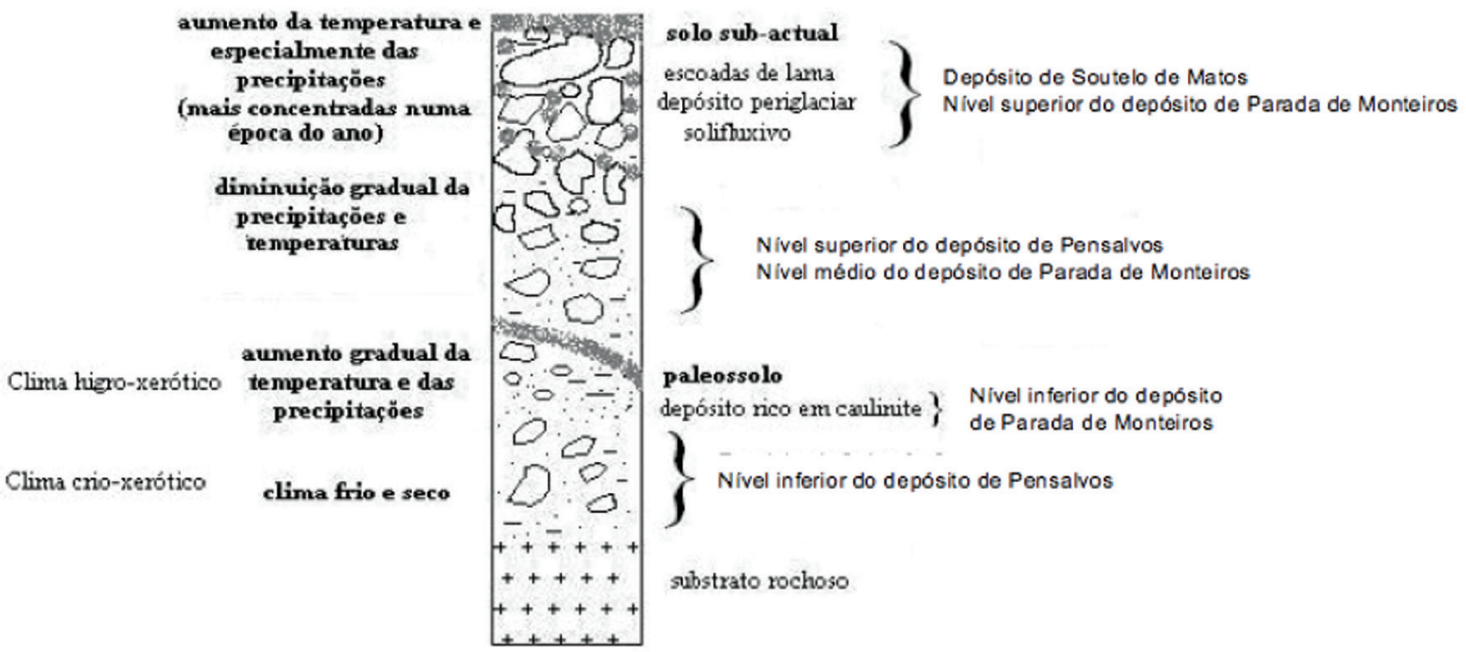

Fig. 2 - Coluna estratigráfica da vertente norte da serra do Alvão. Fonte: B. MARTINS, 2010. 


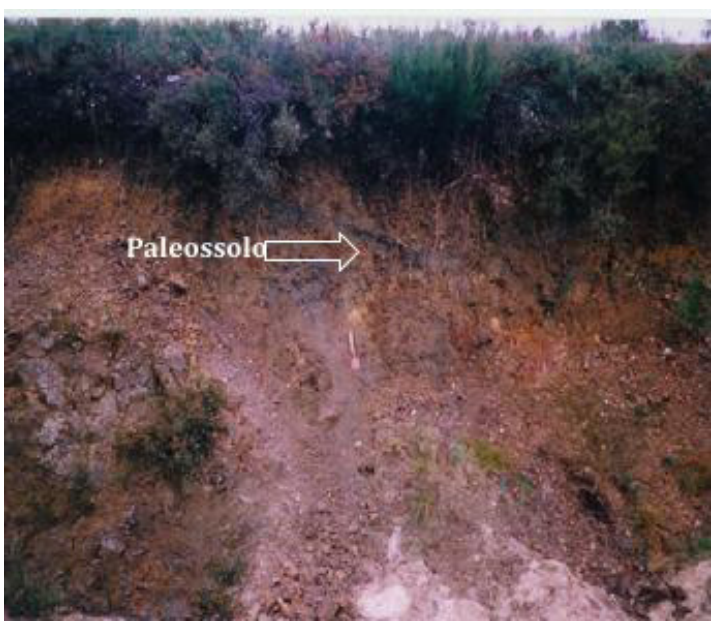

Fig. 3 - Depósito de Pensalvos. A separar os dois níveis do depósito observa-se um paleossolo e um provável ravinamento. Fonte: B. MARTINS, 2010.

mais elevados. Assim, numa primeira fase, o frio teria de ser suficientemente intenso para que o gelo se formasse e atuasse por microgelifracção ao nível da rocha, principalmente nas vertentes desprotegidas de vegetação, mais elevadas e sombrias. Mas teria de existir água no solo suficiente para que a deslocação dos materiais ao longo das vertentes fosse efetiva, mesmo antes de um episódio de aquecimento responsável pelo paleossolo. 0 regresso às condições anteriores poderia ter sido antecedido pelo ravinamento.

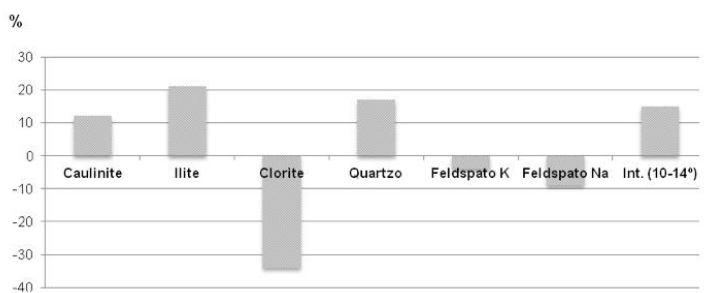

Fig. 4 - Variação mineralógica da fracção argilosa entre os níveis inferior e superior do depósito de Pensalvos. Fonte: B. Martins, 2010.

O aparecimento do paleossolo sugere, pois, que as condições climáticas permitiram a conquista rápida por parte da vegetação de áreas anteriormente dela desprovidas. Este facto limitaria o aquecimento do solo no Verão e favoreceria o seu arrefecimento no Inverno, podendo ser compatível com a existência de retalhos de permafrost, diminuindo a camada ativa no Verão. Infelizmente não foi possível realizar a datação do paleossolo, que apresentou um teor em carbono no sedimento de cerca de $3,14 \%$, mas a ausência de azoto indicou que o seu teor em carbono orgânico é nulo ou próximo disso.

Imediatamente sobre o paleossolo, as caraterísticas periglaciares mantêm-se, estando de início relacionadas com uma diminuição da humidade, associada a um clima frio e seco. Os paleorravinamentos encontrados permitem deduzir a existência de períodos frios e secos, alternando com períodos hipoteticamente menos frios e com maiores quantidades de precipitação que favoreceriam a escorrência e a acumulação dos materiais em depressões.

A alternância de níveis com maiores ou menores quantidades de argila e com gelifractos de dimensão variada poderá relacionar-se, não só com as características das vertentes, nomeadamente ao nível do declive, da exposição e do material rochoso, mas também com a existência de depósitos que regularizassem as vertentes.

\section{Depósito de Soutelo de Matos}

O depósito de Soutelo de Matos regulariza o nível superior do depósito de Pensalvos ao longo de quase toda a vertente, em especial nos sectores de maior declive. É composto por elementos de grandes dimensões, por vezes de dimensão métrica (blocos), predominantemente de natureza granitóide e quartzosa, dispostos de forma caótica, envolvidos por uma grande quantidade de matriz terrosa a sugerir uma movimentação solifluxiva (fig. 5).

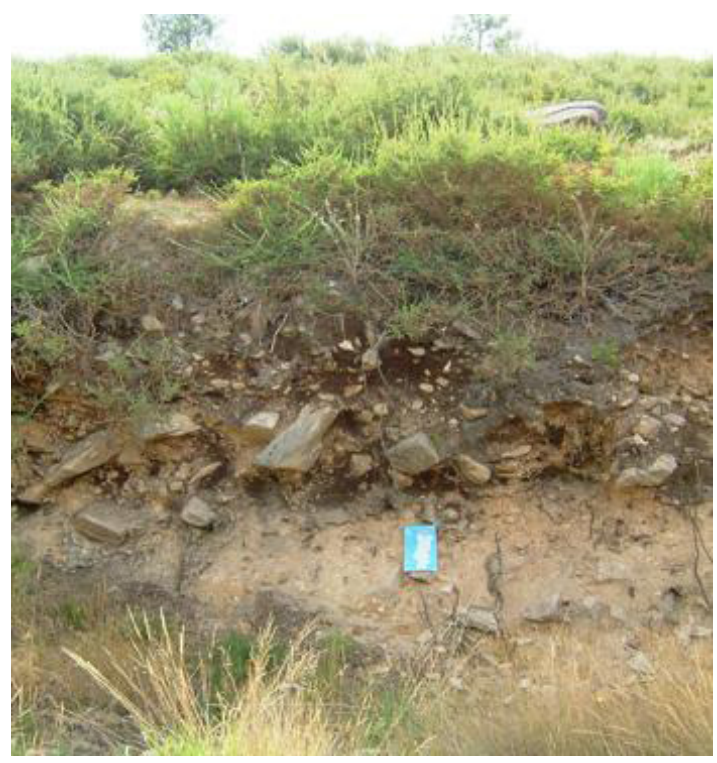

Fig. 5 - Heterogeneidade dos materiais constituintes do depósito de Soutelo de Matos. Fonte: B. MARTINS, 2010.

A matriz silto-argilosa é muito abundante e ao nível da mineralogia da fracção argilosa, a caulinite é o mineral que predomina (fig. 6). É possível ainda verificar duas variantes, uma que parece estar associada a um movimento lento e outra, que se sobrepõe, que faz supor uma movimentação rápida, responsável pela existência de grandes bolsadas preenchidas por clastos heterométricos.

Por esta altura, o principal mecanismo de transporte seria a solifluxão, mais ou menos generalizada durante os episódios de degelo. É possível que, em locais mais elevados, ocorressem condições para que o solo gelasse. 


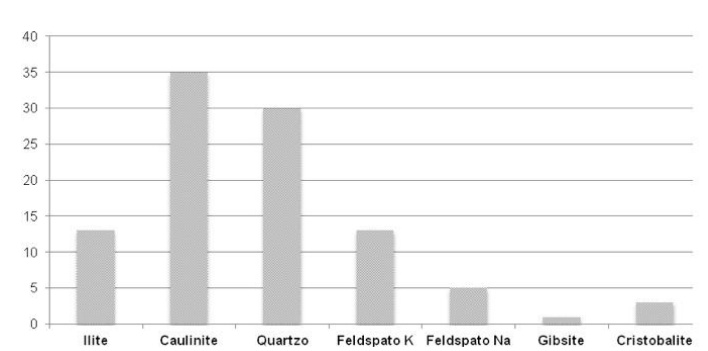

Fig. 6 - Análise mineralógica da fracção argilosa do depósito superior de Soutelo de Matos (valores percentuais). Fonte: B. Martins, 2010.

A análise deste depósito demonstra não só a existência de ciclos de gelo-degelo que permitiriam a fragmentação da rocha, mas também a grande necessidade de água, certamente associada a chuvas e à fusão das neves, que desencadeariam movimentações em massa, em sectores das vertentes, de tipo escoadas de lama de grandes proporções. As amplitudes térmicas anuais seriam elevadas, sendo os materiais movimentados por grandes quantidades de água e depositados em fundos de vale ou pequenas rechãs. O clima seria húmido de modo a permitir a queda de neve, mas suficientemente frio para que se verificasse a gelifracção das rochas, durante uma época do ano. Na época estival, com a subida da temperatura, ocorreria a fusão das neves coincidindo com a época do ano em que ocorreriam os principais movimentos em massa.

Com base nos aspectos geográficos do litoral e das montanhas de Portugal durante o Würm recente, a vertente norte da serra do Alvão encontrar-se-ia numa situação próxima do limite das neves permanentes, que estaria a cerca dos 1200 metros de altitude (CoudéGaussen, 1981; Cordeiro, 1986a, 1986b; Daveau, 1971, 1973; Daveau \& DeVy-Vareta, 1985), o que leva a admitir que a vertente estivesse numa situação de manutenção de neve e formação de gelo com alternância sazonal de gelo-degelo, com características muito próprias das áreas periglaciares.

\section{Os mantos de alteração}

Da análise de alguns mantos de alteração encontrados na área de estudo constatou-se que o processo de meteorização obedeceu a determinadas modificações a nível físico, mineralógico e químico, relativamente comuns em perfis estudados próximos da área (Ferreira, 1979; Braga, 1988, 1990; Martins, 1998; SOARES, 1992, 2008). Os perfis localizam-se na vertente oriental da serra do Alvão, próximo de Telões, a uma cota de cerca de $600 \mathrm{~m}$. Desenvolvemse a meia vertente, num sector de declive a rondar os $12^{\circ}$, em área predominantemente florestal. Do ponto de vista climático, a precipitação neste sector da vertente apresenta uma média anual de $1300 \mathrm{~mm}$
(Daveau, 1977). A litologia de base corresponde ao granito de Vila Pouca de Aguiar (GVPA), o mais representativo do Plutão de Vila Pouca (PVP) (Sılva, 2000). A amostra da rocha sã que serviu de análise encontra-se a poucas dezenas de metros dos perfis analisados. Trata-se do granito predominantemente porfiróide de grão médio, caracterizado pela presença de enclaves microgranulares tonalíticos e granodioríritos acompanhado frequentemente de filões com orientação NNE-SSW coincidentes com a fracturação principal. Os dados geocronológicos U-Pb e isotópicos ( $\mathrm{Rb}-\mathrm{Sr}$ e $\mathrm{Sm}-\mathrm{Nd}$ ) revelam uma idade de $299 \pm 13$ Ma obtidas pelo método U-Pb (MARTINs et al., 1997, 1997b; MARTINS, 1998).

\section{As características do granito em W3}

O granito em W3 caracteriza-se por se apresentar medianamente alterado, menos de $35 \%$ da rocha encontra-se decomposta ou desintegrada para um solo. Em W3 o granito apresenta perda do brilho e da cor inicial de alguns minerais, particularmente as biotites, que apresentam, muitas vezes, um anel de cor com origem ferruginosa, indicando a presença de óxidos de ferro como sinal de alteração. A meteorização iniciase, em geral, pelos planos de macla e de clivagem, sendo a plagioclase e a biotite particularmente sensíveis, contrastando com o quartzo e a moscovite, mais resistentes.

\section{As características do granito em W4}

0 granito em W4 encontra-se muito alterado, com mais de $35 \%$ da rocha desintegrada ou decomposta para um solo. Rocha fresca ou descolorada ainda está presente no maciço. Caracteriza-se ainda pela decomposição dos feldspatos, que se esboroam quase sempre com os dedos, ainda que, por vezes, com alguma dificuldade, desenvolvendo uma estrutura porosa algo incipiente, verificada pelo aumento da percentagem silto-argilosa na matriz do perfil.

\section{As características do granito em W5}

O granito em W5 encontra-se decomposto. A estrutura da rocha original encontra-se preservada, apresenta uma textura claramente porosa, evidenciada pelo aumento da percentagem da fracção silto-argilosa na matriz dos perfis. Os minerais micáceos apresentam uma crescente esfoliação. O quartzo, tal como a moscovite, surge mais baço, por vezes acompanhado de uma auréola de sílica amorfa, com fracturação, Os feldspatos apresentam-se muito alterados, sendo possível observar megacristais deste material embutidos na matriz dos perfis. A meteorização tende a homogeneizar a massa do solo. 
As linhas gerais da meteorização

Do ponto de vista físico, o avanço da meteorização é acompanhado por uma perda da coesão da rocha, acompanhada de uma crescente porosidade da mesma. Do ponto de vista granulométrico, aumenta a percentagem da fracção fina, muito especialmente da fracção siltoargilosa. Ao nível mineralógico, globalmente, verificase uma diminuição das plagioclases e da biotite com o avanço da meteorização. O feldspato potássico mostrase mais resistente, assim como o quartzo e a moscovite. Pela análise das fracções de areia fina a muito fina, silto-argilosa e argilosa, verificou-se que o avanço da meteorização se caracteriza pelo aumento dos minerais secundários e diminuição generalizada dos minerais primários. Numa primeira fase da meteorização, predomina a montmorilonite nas fracções silto-argilosa e argilosa, indicando um processo predominantemente de arenização/bissialitização. Em fases mais avançadas de alteração, verifica-se o avanço da caulinite, sugerindo um processo de monossialitização dos perfis.

Do ponto de vista químico, o avanço da meteorização é acompanhado por perdas significativas de $\mathrm{CaO}$ e $\mathrm{MgO}$ (refletindo uma degradação preferencial das biotites e das plagioclases) acompanhada de ganhos de Al2O3 (relacionado com ofacto desteóxido ficar retido em grande parte nos produtos da meteorização). Asílica apresenta um comportamento irregular, embora se verifiquem perdas nos perfis com estados de meteorização mais elevados.

\section{Cartografia da espessura das formações superficiais}

Devido à elevada variação espacial dos depósitos e à natureza heterogénea dos perfis de meteorização, a inferência da espessura das formações superficiais é uma tarefa difícil, principalmente em meios pouco homogéneos e isotrópicos, como é o caso da área de estudo, quer em termos de topografia, quer litologia de base.
Por outro lado, para o desenvolvimento da metodologia adoptada, é necessária a existência de cortes que permitam a observação das formações superficiais de forma a obter a sua espessura.

Para a área de estudo procedeu-se à amostragem de 48 perfis (amostra) (figura 7). Para cada perfil foi registada a espessura média das formações superficiais. Posteriormente, foi georreferenciado.

Foram realizadas modelações sucessivas, recorrendo a diferentes metodologias de geoestatística e parâmetros de modelação, de forma a otimizar a estimativa e a garantia de qualidade da cartografia produzida, acabando por optar pela krigagem ordinária.

Para a krigagem ordinária ao invés de assumir que a média é constante ao longo de todo o domínio, assume antes que a constante mais próxima de cada ponto influi no valor de outro ponto em que $\mathrm{m}$ (ua) $=\mathrm{m}(\mathrm{u})$ para cada valor de dados na proximidade e $Z$ (ua) é usada para calcular Z (u) (CRÉPIN \& JoHnSON 1993).

Da observação dos vários locais de amostragem verificouse que as espessuras das formações superficiais mais reduzidas ou mesmo inexistentes encontram-se na cumeada da serra. Nas áreas metassedimentares, a espessura das formações superficiais, que correspondem essencialmente a depósitos de vertente, não ultrapassa 2 metros. Nas áreas de granito, os mantos de alteração contribuem para as espessuras mais elevadas, a SE da área de estudo, ultrapassando, por vezes, 5 metros de profundidade. A heterogeneidade dos perfis de alteração nos granitos permite a existência de áreas de elevado grau de meteorização, a par de áreas de maior conservação.

\section{Discussão e conclusões}

De entre os factores que tiveram maior influência na evolução do relevo de Portugal no decurso do final do

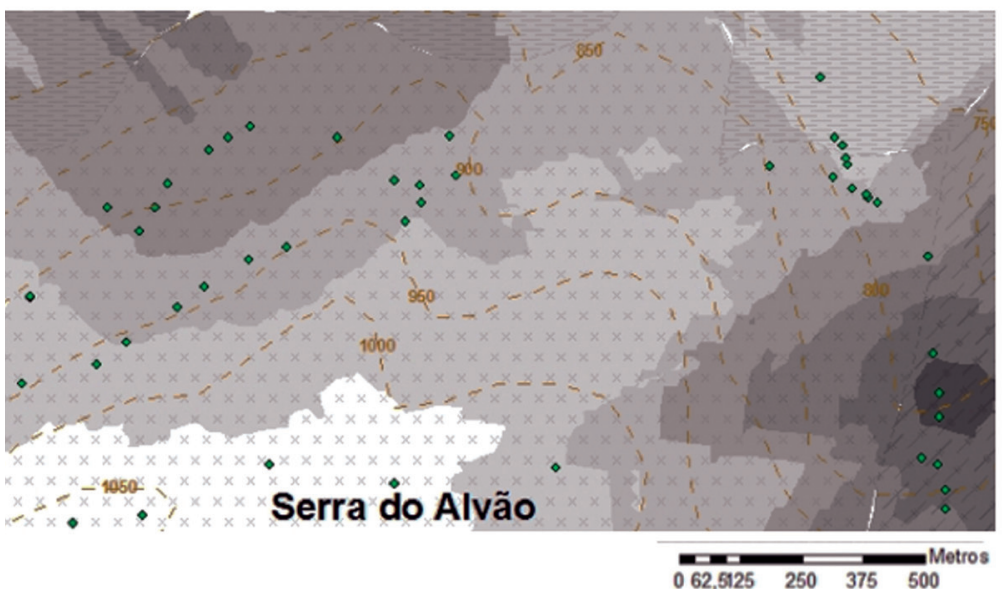

\section{Legenda}

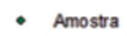

Espessura de Formaçöes Superficiais (cm) Classes

Sem formaçăo superficial

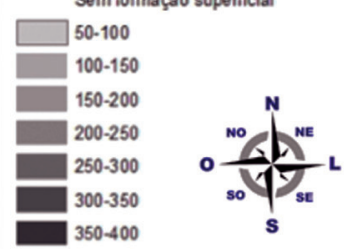

$400-450$

$>450$

Granito de Vila Pouca de Aguiar (pós-tectonico)

Granito de Mineu (sin-tectónico)

Metassedimentos silúricos

$062,5125 \quad 250 \quad 375 \quad 500$

- - - Curvas de Nivel

Fig. 7 - Cartografia da espessura das formações superficiais $(\mathrm{cm})$ e localização dos pontos de amostragem. 
Quaternário é incontestável que o frio e os processos que lhe estão associados tiveram um papel muito importante na modelação das formas de relevo. A par dos depósitos de vertente, em áreas de substrato granítico, os mantos de alteração assumem um papel relevante na dinâmica atual das vertentes (i.e. BATEIRA, 2001; AYdIN \& EGELI, 2001; Aydin, 2006; Pedrosa et al., 2007; Martins, 2010; Santos, 2011). São os depósitos de vertente e os mantos de alteração os elementos que constituem as formações superficiais estudadas. Apresentam uma importante variação ao nível da espessura, mas são os mantos de alteração aqueles onde se encontraram espessuras mais elevadas, ultrapassando por vezes os 5 metros de profundidade (SE da área de estudo).

A cartografia da espessura das formações superficiais sugere alguns tópicos que importa reter. 0 primeiro relaciona-se com as características pouco homogéneas e isotrópicas da área de estudo que dificulta a aplicação de modelos geoestatísticos que implicam necessariamente estimação de valores em locais não amostrados (WEBSTER, 2008). Por outro lado, a introdução das espessuras das formações superficiais, no estudo em particular, a partir de 48 locais de amostragem, depende da existência de locais de observação, não permitindo uma distribuição homogénea nem equitativa dos mesmos. Verificouse antes que existem áreas de elevada concentração de locais onde se observam formações superficiais e onde é possível obter a sua espessura, geralmente relacionados com a existência de trincheiras, e áreas onde não é possível a sua observação. Este facto tem influencia na qualidade da cartografia produzida. Nos locais de elevada concentração de pontos de amostragem o modelo gerado terá um elevado grau de assertividade, nas áreas mais rarefeitas, os resultados serão naturalmente menos positivos.

A krigagem foi o método geoestatístico escolhido na extrapolação dos valores. Das várias modelações desenvolvidas, a krigagem ordinária foi aquele que melhores resultados obteve (Penizek \& Boruvka, 2004), em especial em áreas de características semelhantes, quer do ponto de vista litológico quer morfológico à área de estudo (SANTOS, 2011).

Quando comparada com outros algoritmos, a krigagem ordinária apresenta-se como aquele que consegue a melhor precisão geral (LANDIM, 2000) e permite ainda a avaliação da precisão associada à estimação (CRÉPIN \& JoHNSON, 1993).

A mais valia do modelo desenvolvido relaciona-se com os baixos custos que o modelo acarreta. Permite ainda a introdução de mais medições de espessuras se surgirem novos locais onde seja possível observar formações superficiais. Desta forma é possível melhorar a qualidade da cartografia produzida (SANTOS, 2011). Apesar de ter um carácter estimativo, permite assim, de forma acessível, a produção da cartografia da espessura das formações superficiais e a melhoria dos níveis de confiança acrescentando novos pontos de amostragem.

Os desafios colocados à cartografia da espessura das formações superficiais são proporcionais à importância deste tipo de mapas, nomeadamente no que respeita à dinâmica das vertentes assumindo-se como um importante instrumento para os estudos de riscos geomorfológicos, como por exemplo os riscos de ravinamento e os riscos de deslizamentos (REBELo, 2001, 2003) tão úteis em trabalhos de planeamento e de ordenamento do território.

\section{Bibliografia}

Arenas, R., Farias, P., Gallastegui, G., Gil Ibarguchi, J.I., González Lodeiro, F., Klein, E., Marquínez, J., Martín Parra, L.M., Martínez Catalán, J.R., Ortega, E., de Pablo Maciá, J.G., Peinado, M., e Rodríguez FERnándeZ, L.R. (1988) - “Características geológicas y significado de los dominios que componen la Zona de Galicia-Trás-os-Montes": Actas del II Congreso Geológico de España, Simposios, p. 75-84.

Aydin, A. \& EgELI, I. (2001) - "Stability of slopes cut in metasedimentary saprolites in Hong Kong". Bull. Eng. Geol. Env., 60, p. 315-319.

AYDIN, A. (2006) - "Stability of saprolotic slopes: nature and the role of field scale heterogeneities, Natural Hazards And Earth System Sciences, European Geosciences Union.

Bateira, C. (2001) - Movimentos de Vertente no NW de Portugal: Susceptibilidade Geomorfológica e Sistemas de Informação Geográfica. Tese de Doutoramento, apresentada à Faculdade de Letras da Universidade do Porto.

Braga, Maria Amália Sequeira (1988) - Arenas e Depósitos Associados da Bacia de Drenagem do Rio Cávado, Portugal: Contribuição para o Estudo da Arenização. Tese de Doutoramento, apresentada à Universidade do Minho, 325 p. + Anexos + 6 Mapas Dobrados.

Braga, Maria Amália Sequeira (1990) - “Arenas e depósitos associados da bacia de drenagem do rio Cávado, Portugal: Contribuição para o estudo da arenização". Gaia, Revista de Geociências, n².

Chaline, Jean (1985) - Histoire de l'homme et des climats au Quaternaire. Paris, Doin, .366 p.

Cordeiro, A. M. Rochette (1986a) - Evolução de Vertentes na Serra da Freita. Coimbra (policopiado).

Cordeiro, A. M. Rochette (1986b) - "Nota preliminar sobre formas e formações periglaciares na Serra da 
Freita“. Cadernos de Geografia, Coimbra, 5, p. 161-172.

Cordeiro, A. M Rochette (1990) - "O depósito de Varzielas (Serra do Caramulo): Contribuição para o estudo do Tardiglaciar wurmiano em Portugal". Cadernos de Geografia, Coimbra, 9, p. 49-59.

Cordeiro, A.M. Rochette (1992) - “O Homem e o meio no Holocénico português. Paleo-ambientes e erosão". Mediterrâneo, Universidade Nova de Lisboa, 1, p. 89-109.

CoRdeIRO, A.M. Rochette (1995) - “A provável evolução paleoclimática do Pleistocénico final no Centro Litoral de Portugal (Montanhas Ocidentais)". Actas da $3^{a}$ Reunião do Quaternário Ibérico, Coimbra, p. 38-48.

Coudé-Gaussen, Geneviève (1981) - Les Serras da Peneda e do Gerês. Lisboa, CEG, Memórias, 5, 254 p.

CRÉPIN, J. \& JoHnson, R. L. (1993) - "Soil sampling for environmental acess". In: Carter, M. R. (Ed), Spoil Sampling And Methods Of Analysis. Lewis Publisher, p 5-18.

Daveau, Suzanne (1971) - "La glaciation de la Serra da Estrela”. Finisterra, Lisboa, CEG, 6 (11), p. 5-40.

Daveau, Suzanne (1973) - "Quelques exemples d'évolution quaternaire des versants au Portugal". Finisterra, Lisboa, CEG, 8 (15), p. 5-47.

Daveau, Suzanne \& Devy-Vareta, Nicole (1985) "Gélifraction, nivation, et glaciation d'abri de la Serra da Cabreira”. Actas da I Reunião do Quaternário Ibérico, Lisboa, Vol.1, p.75-84.

Farias, P.; Gallastegui, G.; González Lodeiro, L.; Marquinez, J.; Martin Parra, L. M.; MArtinez Cataln, J. R.; Pablo Maciá, J. G. \& Rodriguez Fernandez, L. R. (1987) - “Aportaciones al conocimiento de la litoestratigrafia y estructura de Galicia Central". Memórias Mus. Labor. Miner. Geológico Fac. Ciências da Universidade do Porto, 1, p. 411-431.

GoovaerTs, P. (1999) - "Geostatistics in soil science: stateof-the art and perspectives". Geoderma, Elsevier, 89, p. 1-45.

Ferreira, A. Brum (1979) - "Os mantos de alteração e o modelado das regiões graníticas: Ideias Recentes e orientações de pesquisas". Finisterra, Lisboa, CEG, 14 (28), p. 218-244.

IEAG (1981) - "Rock And Soil Description And Classification For Engineering Geological Mapping”. Bull. leag, Essen, 24, p. 235-274.

ISRM (1980) - "Rock Characterization Testing And Monitoring“. Isrm Suggested Methods, Edition Et. Brown.
Julivert, M.; Fontboté, J. M.; Ribeiro, A. \& Conde, L. (1974) - Mapa Tectónico de la Península Ibérica y Baleares. Escala 1/100 000. Memoria Explicativa. Madrid, Instituto Geológico y Minero de España, 113 p.

LandiM, P.M.B. (2000) - Introdução aos Métodos de Estimação Espacial para Confecção de Mapas. Dga, Igce, Unesp/Rio Claro, Lab. Geomatemática, Texto Didático 02, $20 \mathrm{p}$. Disponível em http://www.Rc.Unesp.Br/lgce/ Aplicada/Textodi.Htm.

LOWE, J. \& WALKER, M. (1984) - Reconstruction Quaternary Environments. New York, Longman, 389 p.

Martins, Bruno (2010) - A Depressão de Régua-ChavesVerin: Contributo para Análise do Risco de Ravinamento. Tese de Doutoramento, apresentada à Faculdade de Letras da Universidade de Coimbra, 396 p.

Martins, H.C.B. (1997) - Evolução geoquímica dos granitóides biotíticos tarditectónicos e póstectónicos do Quadrângulo Vieira do MinhoMoreira de Rei-Vila Pouca de Aguiar-Boticas. Estudo comparativo, Actas. IX Semana de Geoquímica, IV Congresso de Geoquímica dos Países de Língua Portuguesa, Braga, p. 87-90.

MARTINS, H.C.B. (1998) - Geoquímica e petrogénese de granitos biotíticos tarditectonicos e póstectonicos. Implicações metalogénicos. Tese de doutoramento,Universidade de Trás-dosMontes e Alto Douro.

Pedrosa, António de Sousa (1993) - Serra do Marão: Estudo de Geomorfologia. Tese de Doutoramento, Faculdade de Letras da Universidade do Porto, Porto, 3 vols.

Pedrosa, A.; Marques, B.; Martins, B.; Sousa, J. (2007) "Quaternary evolution of the Serra do Marão and its consequences in the present dynamics", Territorium, , 14, p. 33-43.

Penizek, V. \& Boruvka, L. (2004) - "Processing of conventional soil survey data using geostatistical methods". Plant Soil And Environment , 50, p. 352-357.

Rebelo, Fernando (1985) - “Contribuição para o conhecimento do modelado periglaciar de baixa altitude em Portugal". Actas da $1^{a}$ Reunião do Quaternário Ibérico, Lisboa, Vol.1, p. 121-139.

Rebelo, Fernando (1986) - "Modelado periglaciar de baixa altitude em Portugal”. Cadernos de Geografia, Coimbra, 5, p. 127-137.

Rebelo, Fernando (2001) - Riscos Naturais e Acção Antrópica. Coimbra, Imprensa da Universidade, 274 p. 
Rebelo, Fernando (2003) - Riscos Naturais e Acção Antrópica. Estudos e Reflexões. Coimbra, Imprensa da Universidade, 286 p. (2 ${ }^{\text {a }}$ edição revista e aumentada).

Rebelo, Fernando (2007) - "O risco de sedimentação na laguna de Aveiro: Leitura actual de um texto de Amorim Girão (1922)“. Territorium, 14, p.63-69.

Santos, Patrícia (2011) - Cartografia de Espessura de Alteração numa Zona Piloto da Margem do Douro através de Métodos Sísmicos: Implicações para o Ordenamento do Território. Tese de Doutoramento apresentada à Faculdade de Ciências da Universidade do Porto, p. 230.

SOARES, Laura (1992) - As Serras de Campelos e Margotos. Contributo para um estudo de morfologia granítica. Tese de Mestrado em Geografia Física, apresentada à Faculdade de Letras da Universidade de Coimbra.

SoARes, Laura (2008) - A Influência das Formações Superficiais no Âmbito dos Processos de
Erosão Hídrica e Movimentos de Vertente no NW de Portugal. Tese de Doutoramento em Geografia Física, apresentada à Faculdade de Letras da Universidade do Porto, 850 p.

VIEIRA, Gonçalo (2000) - "Glacial and periglacial data integration in a GIS: Methodology used in the Serra da Estrela, Portugal”, Geological Quarterly, Warsaw, 44 (1), p 27-31.

VIEIRA, Gonçalo (2004) - Geomorfologia dos Planaltos e Altos Vales da Serra da Estrela. Ambientes Frios do Plistocénico Superior e Dinâmica Actual. Tese de Doutoramento em Geografia, especialidade de Geografia Física, apresentada à Universidade de Lisboa, 724 p. +1 mapa.

Webster, R. (2008) - "Soil science and geoestatistics. Soil geography and geostatistics. Concepts and applications"; In Krasilnikov, P.; Carré, F. E Montanarella, L. (Eds.); Scientific And Technical Report, p. 1-11. 